\title{
SISTEM KONTROL DUA TIPE TIRAI MENGGUNAKAN SENSOR CAHAYA DAN APLIKASI ANDROID BERBASIS ARDUINO UNO
}

\author{
Denny Wijanarko ${ }^{1}$, Ahmad Munawir ${ }^{2}$ \\ ${ }^{1,2}$ Program Studi Teknik Komputer, Jurusan Teknologi Informasi, Politeknik Negeri Jember \\ 1dennywijanarko@gmail.com, ${ }^{2}$ ahmadmunawir107@gmail.com
}

\begin{abstract}
Abstrak
Berkembangnya zaman menuntut seseorang untuk bekerja lebih keras lagi untuk memenuhi kebutuhannya, sehingga kurang memiliki waktu yang cukup dalam mengurus keadaan rumah. Pekerjaan rumah sederhana yang sering dilupakan oleh seseorang adalah membuka tirai di pagi hari dan menutup tirai pada malam hari. Tirai berperan penting dalam pencahayaan suatu rumah atau gedung. Oleh karena itu untuk memberikan kemudahan dalam membuka dan menutup tirai rumah maka perlu dibangun sebuah sistem kontrol otomatis berbasis Arduino Uno untuk dua tipe tirai menggunakan sensor cahaya LDR dan dapat pula dikontrol melalui aplikasi berbasis Android. Tirai nantinya akan membuka dan menutup secara otomatis berdasarkan intensitas cahaya yang diterima oleh sensor LDR. Sistem pada aplikasi Android ini berguna untuk mengontrol tirai ketika seseorang jauh dari rumah dan atau pemilik rumah lupa untuk menutup tirai rumahnya.
\end{abstract}

Kata kunci : tirai, arduino uno, sensor cahaya, dan andorid

\section{Pendahuluan}

Kebutuhan rumah tangga yang semakin meningkat mengharuskan seseorang untuk bekerja lebih keras lagi, sehingga makin sedikitnya waktu yang dimiliki seseorang untuk mengurus keadaan didalam rumahnya. Kegiatan yang sering dilakukan didalam kehidupan rumah tangga,dan biasa kita sering lupa menutup tirai pada malam hari,dan membuka tirai pada pagi hari saat kita tinggal berpergian dari pagi hingga malam.

Dari permasalahan tersebut, maka perlu dibangun sebuah sistem yang dapat membuka dan menutup tirai secara otomatis menggunakan sensor cahaya LDR dan aplikasi android berbasis arduino. Maka dengan adanya alat ini dapat bermanfaat untuk perlengkapan rumah tangga. Sehingga kita tidak perlu khawatir lagi jika lupa menutup dan membuka tirai karena sudah berjalan dengan otomatis.

\section{Tinjauan Pustaka}

\subsection{Sensor Cahaya LDR}

Sensor cahaya LDR (Light Dependent Resistor) merupakan suatu jenis resistor yang peka terhadap cahaya. Nilai resistansi LDR akan berubah-ubah sesuai dengan intensitas cahaya yang diterima. Jika LDR tidak terkena cahaya maka nilai tahanan akan menjadi besar (sekitar 10M $\Omega$ ) dan jika terkena cahaya nilai tahanan akan menjadi kecil (sekitar $1 \mathrm{k} \Omega$ ) (Novianty,Lubis, \& Tony, 2012).

\subsection{Android}

Pengertian Android menurut Safaat (2015), android adalah sebuah sistem operasi untuk mobile berbasis linux yang mencakup sistem operasi, middleware dan aplikasi. Android menyediakan platform terbuka bagi para pengembang untuk menciptakan aplikasi mereka. Sistem operasi yang mendasari Android dilisensikan dibawah GNU, General Public Lisence Versi 2v(GPL2v2), yang sering dikenal dengan istilah "copyleft" lisensi dimana setiap perbaikan pihak ketiga harus terus jatuh dibawah terms.

\subsection{Arduino Uno}

Arduino adalah sebuah board mikrokontroller yang berbasis ATmega328. Arduino memiliki 14 pin input/output yang mana 6 pin dapat digunakan sebagai output PWM, 6 analog input, crystal osilator $16 \mathrm{MHz}$, koneksi USB, jack power, kepala ICSP, dan tombol reset. Arduino mampu mensupport mikrokontroller; dapat dikoneksikan dengan komputer menggunakan kabel USB. (Feri Djuandi, 2011).

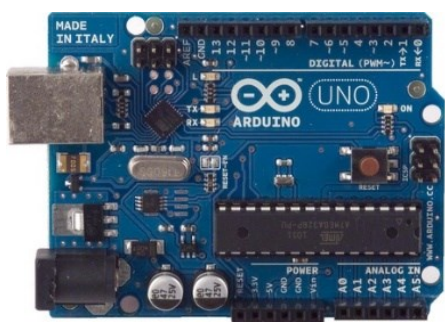

Gambar 1. Board Arduino Uno 


\subsection{Motor DC}

Motor DC adalah jenis motor listrik yang bekerja menggunakan sumber tegangan DC. Motor DC atau motor arus searah sebagaimana namanya, menggunakan arus langsung dan tidak langsung/direct-unidirectional. Motor DC digunakan pada penggunaan khusus dimana diperlukan penyalaan torque yang tinggi atau percepatan yang tetap untuk kisaran kecepatan yang luas.

\subsection{Bluetooth}

Menurut Sugiri (2004:5) Bluetooth beroperasi dalam pita frekuensi $2,4 \mathrm{GHz}$ (antara $2.402 \mathrm{GHz}$ sampai $2.480 \mathrm{GHz}$ ) yang mampu menyediakan layanan komunikasi data dan suara secara real-time antara host to host bluetooth dengan jarak jangkauan layanan yang terbatas. Bluetooth dapat berupa card yang bentuk dan fungsinya hampir sama dengan card yang digunakan untuk wireless local area network (WLAN) dimana menggunakan frekuensi radio standar IEEE 802.11, hanya saja pada bluetooth mempunyai jangkauan jarak layanan yang lebih dekat dan kemampuan transfer data yang lebih rendah.

\section{Metode Kegiatan}

\subsection{Metode Pelaksanaan}

Dalam penelitian dengan judul "Sistem Kontrol Dua Tipe Tirai menggunakan Sensor Cahaya Dan Aplikasi Android Berbasis Arduino Uno" ini menggunakan tahapan metode pelaksanaan seperti pada gambar 1 .

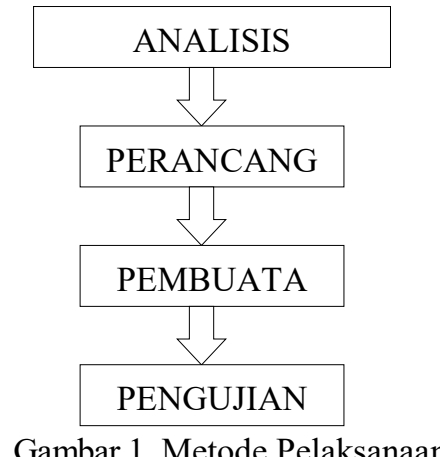

\subsection{Perancangan Sistem}

Dalam merancang sistem kontrol tirai ini dilakukan perancangan alat kontrol agar sesuai dengan perencanaan. Perangkat kontrol tersebut diantaranya adalah sebuah perangkat sensor cahaya dan android smartphone sebagai penerima perintah, Modul bluetooth HC-05 sebagai media penghubung antara android smarthphone dengan Arduino, Arduino sebagai alat kontrol, Modul relay sebagai penghubung antara Arduino dan motor.

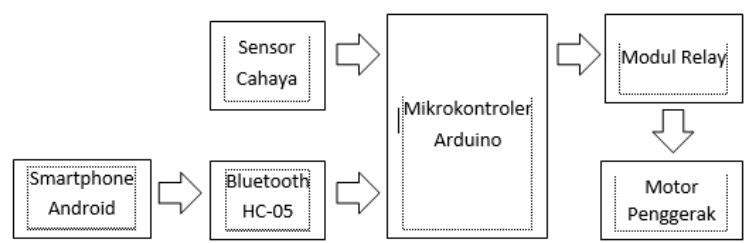

Gambar 2. Blok diagram rangkaian

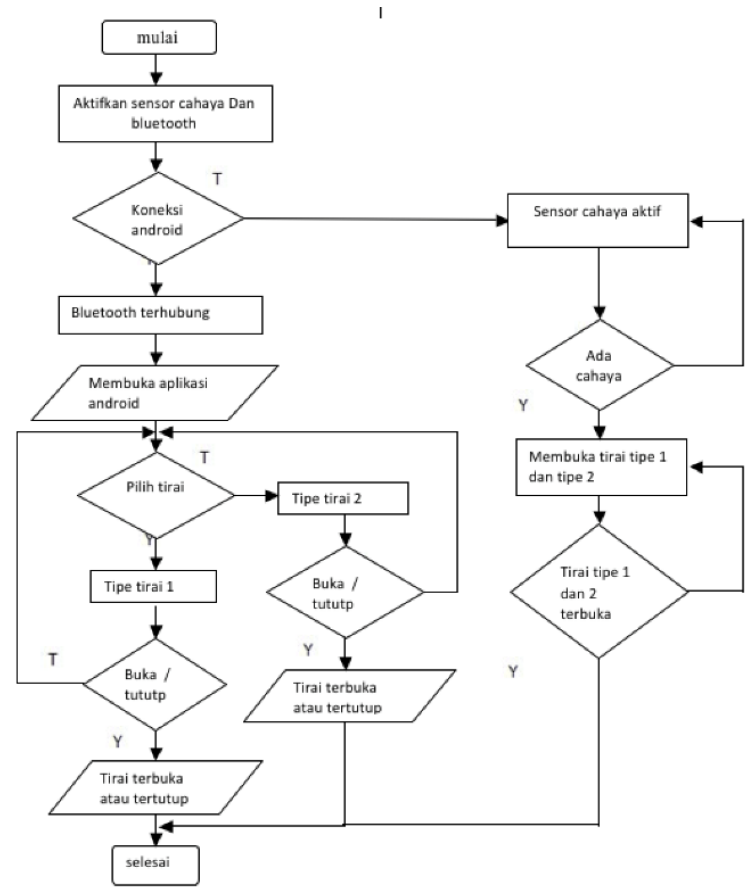

Gambar 3. flowchart

\section{Hasil Dan Pembahasan}

\subsection{Analisis Kebutuhan}

Berbaga referensi didapatkan dari Buku Pustaka, penelitian yang telah ada sebelumnya serta melalui media internet untuk mengumpulkan data dan informasi yang diperlukan untuk analisis kebutuhan untuk pelaksanaan kegiatan penelitian ini. Penulis melakukan percobaan terhadap Arduino, sebagai mikrokontroler untuk mengkontrol motor sebagai outputan. Arduino dan relay modul juga diperlukan untuk melakukan kontrol terhadap motor dimana motor memerlukan sebuah driver (transistor, relay) antara mikrokontroler agar dapat saling terhubung dan mengkontrolnya.

\subsection{Perancangan Hardware Keseluruhan Sistem}

Berikut keseluruhan Perancangan perangkat keras (hardware) bagian yaitu sebagai kontrol sistem utama.Pada penelitian ini sistem perangkat keras dan komponen utama terdiri dari mikrokontroler arduino uno, motor, module step down, servo, relay, power input dari tegagnan 220 volt AC, bluetooth HC-05 untuk menunjang 
masukan (input) menggunakan smartphone android, LDR (Light Dependent Resistor), dan Limit Switch.

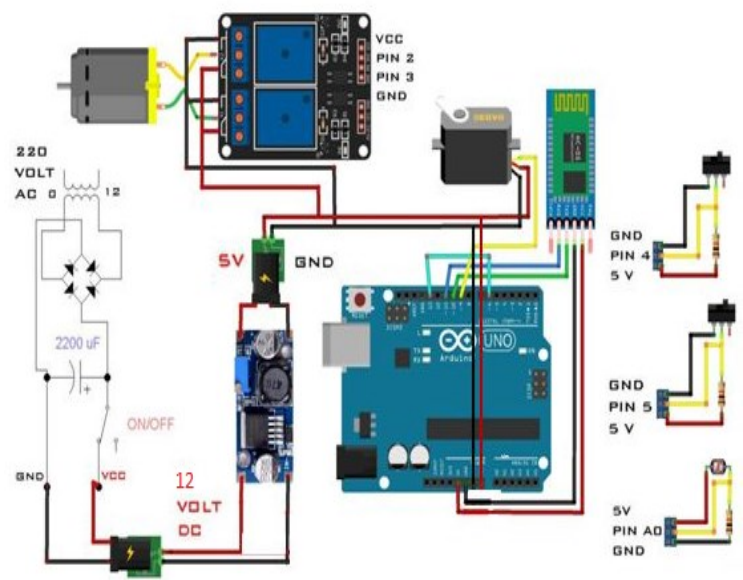

Gambar 4. Alur Perancangan Hardware Utama

\subsection{Pembuatan}

\subsubsection{Pembuatan Perangkat keras (hardware)}

Perangkat keras berupa sistem rangkaian elektronika, mekanik sebagai media untuk peletakan semua perangkat keras.

\subsubsection{Diagram Blok Sistem}

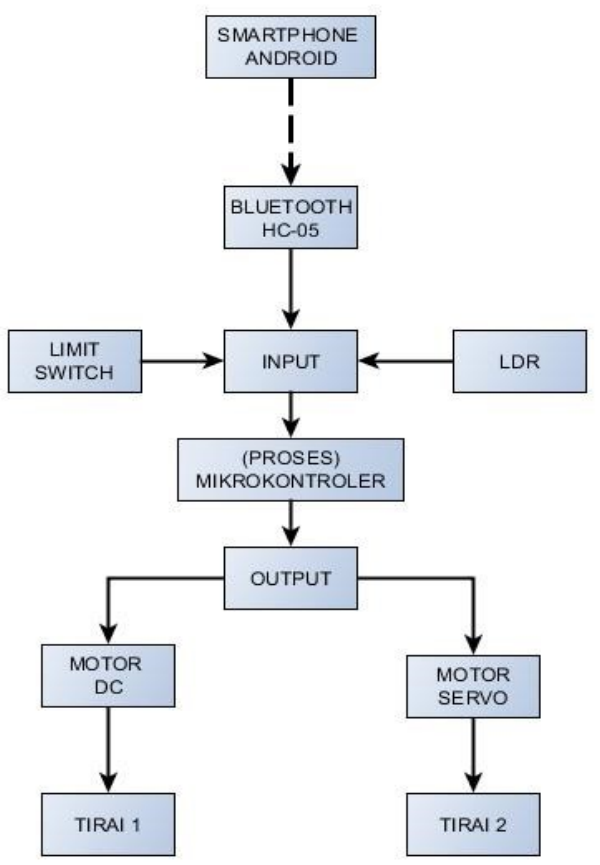

Gambar 5. Diagram Blok Sistem

\subsubsection{Konfigurasi Board Arduino Uno}

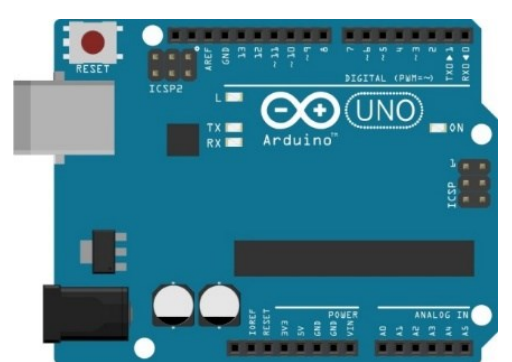

Gambar 6. Bentuk Fisik Arduino Uno

Berikut ini adalah pembagian dari masingmasing port mikrokontoler arduino yang digunakan pada koneksi antar hardware yaitu :

1. Pin digital 4 dan 5 terhubung langsung pada pin rangkaian limit switch.

2. Pin digital 9 terhubung dengan sebuah motor servo.

3. Pin digital 10 dan 11 diset sebagai pin serial yaitu TX (Transmitter) dan RX (Receiver), pin ini terhubung dengan module bluetooth HC-05 secara serial.

4. Pin digital 2 dan 3 terhubung dengan module relay 2 channel untuk menggerakkan sebuah motor DC.

5. Pin analog 0 terhubung dengan rangkaian sensor cahaya LDR.

6. Soket 220 volt AC yang tegangannya diturunkan menjadi 12 volt DC terhubung sebagai catu daya utama mikrokontroler Arduino Uno.

\subsubsection{Konfigurasi Bluetooth HC-05}

Kabel jumper digunakan untuk mengkoneksikan Bluetooth HC-05 dengan arduino uno. Bluetooth HC-05 yang pertama yaitu pin RX (receiver) dihubungkan pada pin 11, sementara pin TX (transmitter) dihubungkan dengan pin $10, \mathrm{VCC} 5 \mathrm{~V}$ dan GND juga dihubungkan dengan board arduino uno. Konfigurasi penyambungan koneksi penghubung antara $\mathrm{HC}-05$ dengan Arduino Uno

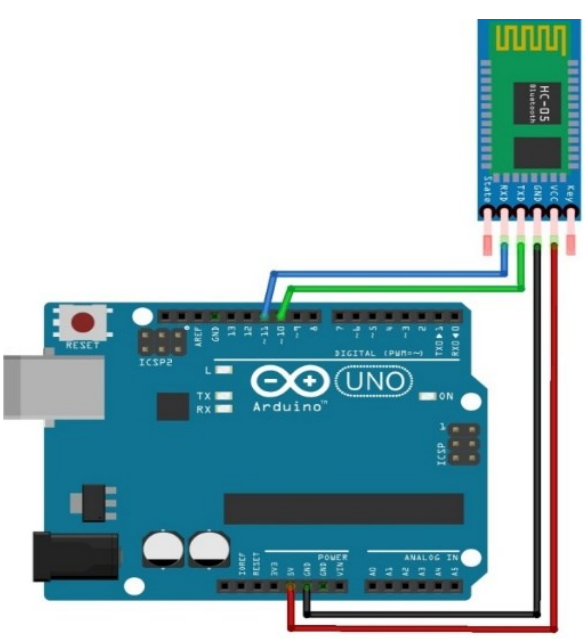

Gambar 7. Konfigurasi Bluetooth HC-05 


\subsubsection{Pembuatan Rangkaian Sensor Cahaya LDR (Light Dependent resistor)}

1. Rangkaian sensor garis tersusun atas LDR (Light Dependent resistor) dan resistor.

2. LDR (Light Dependent resistor)

3. Resistor bernilai $10 \mathrm{KOhm}$ berfungsi sebagai pull-up tegangan input menuju pin.

4. Apabila sensor mengenai cahaya maka nilai output dari rangkaian akan bernilai semakin besar.

5. Apabila sensor tidak mengenai cahaya maka nilai output dari rangkaian akan bernilai semakin kecil.

6. Sensor cahaya ini sudah terintegrasi dan output berupa analog.

Skematik Pembuatan Rangkaian sensor cahaya secara menyeluruh :

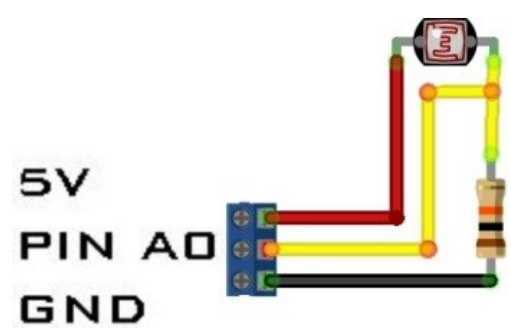

Gambar 8. Rangkaian Sensor Cahaya LDR

\subsubsection{Aplikasi Program Arduino}

Arduino adalah sebuah module mikrokontroler dengan port input dan output yang diprogram menggunakan bahasa C, Arduino Compiler / IDE arduino digunakan untuk mengkompile bahasa $\mathrm{C}$ arduino dan juga untuk mengupload program hasil compile tersebut (hex file) ke board Arduino. Jalankan IDE Arduino dengan menjalankan sebuah file bernama arduino.exe pada lokasi software Arduino.

\subsubsection{Aplikasi Program Android}

Android adalah sistem operasi yang berbasis Linux untuk telepon seluler seperti telepon pintar dan komputer tablet. Android menyediakan platform terbuka bagi para pengembang untuk menciptakan aplikasi mereka sendiri untuk digunakan oleh bermacam peranti bergerak. Awalnya, Google Inc. Android memiliki berbagai keunggulan sebagai software yang memakai basis kode komputer yang bisa didistribusikan secara terbuka (open source) sehingga pengguna bisa membuat aplikasi baru di dalamnya. aplikasi program android menggunakan App Inventor

\subsection{Pengujian}

\subsubsection{Pengujian Koneksi Smartphone Android dan Mikrokontroler}

Pengujian dilakukan dengan menguji koneksi antara module bluetooth pada mikrokontroler dan bluetooth pada smartphone android dengan membuka aplikasi dengan tampilan awal tidak terkoneksi kemuadian pilih berubah terkoneksi.

Tabel 1. Pengujian Koneksi

\begin{tabular}{|l|l|l|l|}
\hline No. & Perintah & $\begin{array}{l}\text { Jarak } \\
\text { (Meter) }\end{array}$ & $\begin{array}{l}\text { Status } \\
\text { Koneksi }\end{array}$ \\
\hline 1 & KONEKSI & 5 & Terhubung \\
\hline 2 & KONEKSI & 6 & Terhubung \\
\hline 3 & KONEKSI & 7 & Terhubung \\
\hline 4 & KONEKSI & 8 & Terhubung \\
\hline 5 & KONEKSI & 9 & Terhubung \\
\hline 6 & KONEKSI & 10 & Terhubung \\
\hline 7 & KONEKSI & 11 & Tdk \\
\hline
\end{tabular}

\subsubsection{Prosedur Pengujian}

1. Aktifkan koneksi bluetooth smartphone android

2. Sandingkan antara bluetooth mikrokontrol dengan bluetooth smartphone

3. Buka aplikasi smartphone android

4. Pilih module bluetooth yang sesuai

\subsubsection{Pengujian LDR}

Pengujian logika sensor cahaya dengan motor DC dan motor servo, pengujian ditampilakan pada tabel berikut:

Tabel 2. Pengujian LDR

\begin{tabular}{|c|c|c|c|c|}
\hline No. & $\begin{array}{l}\text { Nilai } \\
\text { LDR }\end{array}$ & $\begin{array}{l}\text { Motor } \\
\text { DC }\end{array}$ & Servo & $\begin{array}{l}\text { Keadaan } \\
\text { Tirai }\end{array}$ \\
\hline 1 & $<\quad 200$ & $\mathrm{CW}$ & $0^{0}$ & Tertutup \\
\hline 2 & $>\quad 200$ & $\mathrm{CCW}$ & $90^{\circ}$ & Terbuka \\
\hline 3 & $<\quad 200$ & $\mathrm{CW}$ & $0^{0}$ & Tertutup \\
\hline 4 & $>\quad 200$ & $\mathrm{CCW}$ & $90^{0}$ & Terbuka \\
\hline 5 & $<200$ & $\mathrm{CW}$ & $0^{0}$ & Tertutup \\
\hline 6 & $>\quad 200$ & $\mathrm{CCW}$ & $90^{\circ}$ & Terbuka \\
\hline 7 & $<200$ & $\mathrm{CW}$ & $0^{0}$ & Tertutup \\
\hline 8 & $>\quad 200$ & $\mathrm{CCW}$ & $90^{0}$ & Terbuka \\
\hline 9 & $<200$ & $\mathrm{CW}$ & $0^{0}$ & Tertutup \\
\hline 10 & $>\quad 200$ & $\mathrm{CCW}$ & $90^{0}$ & Terbuka \\
\hline
\end{tabular}

\subsubsection{Pengujian tombol smartphone android}

Pada aplikasi smartphone android terdapat beberapa tombol, masing-masing mempunyai perintah yang berbeda, berikut pengujian tombol smartphone android: 
Tabel 3. Pengujian Tombol Tirai 1

\begin{tabular}{|l|l|l|}
\hline No & Tombol & $\begin{array}{l}\text { Pergerakan } \\
\text { Tirai 1 }\end{array}$ \\
\hline 1 & Tirai 1 Buka & Terbuka \\
\hline 2 & Tirai 1 Tutup & Tertutup \\
\hline 3 & Tirai 1 Buka & Terbuka \\
\hline 4 & Tirai 1 Tutup & Tertutup \\
\hline 5 & Tirai 1 Buka & Terbuka \\
\hline 6 & Tirai 1 Tutup & Tertutup \\
\hline 7 & Tirai 1 Buka & Terbuka \\
\hline 8 & Tirai 1 Tutup & Tertutup \\
\hline 9 & Tirai 1 Buka & Terbuka \\
\hline 10 & Tirai 1 Tutup & Tertutup \\
\hline
\end{tabular}

Tabel 4. Pengujian Tombol Tirai 2

\begin{tabular}{|l|l|l|}
\hline No. & Tombol & $\begin{array}{l}\text { Pergerakan } \\
\text { Tirai 2 }\end{array}$ \\
\hline 1 & Tirai 2 Buka & Terbuka \\
\hline 2 & Tirai 2 Tutup & Tertutup \\
\hline 3 & Tirai 2 Buka & Terbuka \\
\hline 4 & Tirai 2 Tutup & Tertutup \\
\hline 5 & Tirai 2 Buka & Terbuka \\
\hline 6 & Tirai 2 Tutup & Tertutup \\
\hline 7 & Tirai 2 Buka & Terbuka \\
\hline 8 & Tirai 2 Tutup & Tertutup \\
\hline 9 & Tirai 2 Buka & Terbuka \\
\hline
\end{tabular}

\section{Kesimpulan Dan Saran}

\subsection{Kesimpulan}

Dari hasil pembahasan tentang Pengendali Jendela Jarak Jauh Menggunakan Arduino Dengan Aplikasi Berbasis Android, dapat di ambil kesimpulan:

1. Dengan adanya penerapan sistem kontrol pada motor menggunakan arduino uno, maka membuka dan menutup tirai dapat dilakukan dengan mudah dan efisien waktu.

2. Menggunakan aplikasi android pada tugas akhir ini akan memudahkan dalam membuka atau menutup tirai.

3. Sistem berjalan dengan baik sesuai rencana ketika siang hari (cerah) tirai akan terbuka, lalu pada saat malam hari tirai akan menutup.

\subsection{Saran}

Untuk pengembangan lebih lanjut tentang Pengendali Jendela Jarak Jauh Menggunakan Arduino Dengan Aplikasi Berbasis Android penulis memberikan saran yaitu:
1. Pada lingkup ini penulis hanya mengimplementasikannya dengan sebuah prototipe rumah, sehingga diharapkan bisa untuk dikembangkan dan diterapkan pada tirai sebenarnya.

2. Pengembangan menggunakan modul komunikasi dengan jarak yang lebih jauh dari Bluetooth.

\section{Daftar Pustaka:}

Novianti, K., Lubis, C., dan Tony, 2012, Perancangan Prototipe Sistem Penerangan Otomatis Ruangan Berjendela berdasarkan Intensitas Cahaya, Seminar Nasional Teknologi Informasi.

Safaat . 2015. Pengertian dan Tingkatan Versi Android.http://seputarti.com/android/pengertian -dan-tingkatan-versi-android.html

Djuandi,Feri.(2011).Pengenalan Arduino. www.tobuku.com, [ 10 Mei 2016]

Eko Sanjaya, 2013. Simulasi Tirai Otomatis Berbasis Mikrokontroler AT89D51. SistemKomputer,Uneversitas Gunadarma. Andi Dharmawan, 2011. Purwarupa Sistem Otomasi Buka Tutup Tirai Berbasis Light Dependent Resistor. Ilmu Komputer dan Elektronika, Universitas Gadjah Mada 